\title{
Determinants of severity levels of anemia among children aged 6-59 months in Ethiopia: further analysis of the 2011 Ethiopian demographic and health survey
}

Kindie Fentahun Muchie]

\begin{abstract}
Background: Childhood anemia is the major public health problem in Ethiopia. It has been implicated with growth retardation, impaired motor and cognitive development, and childhood morbidity and mortality. Thus this study aimed to identify determinants of severity levels of anemia in children aged 6 to 59 months in Ethiopia.

Method: The study was further analysis of the 2011 Ethiopian Demographic and Health Survey. A total of 7636 children aged 6 to 59 months with complete information on the selected predictors were included in the analysis. Proportional odds model of ordinal logistic regression was used to identify determinant factors. Chi-square test of parallelism was used to evaluate the appropriateness of proportional odds assumption. A p-value less than 0.05 was considered as statistically significant.

Results: The Chi-square test of parallelism showed that the odds ratios were constant across all cut-off points of childhood anemia status at $5 \%$ level $(p$-value $=0.071)$. Of the total children sampled, 28.6 and $21.7 \%$ of them were severely/moderately and mildly anemic, respectively. Wasting, Stunting, religion, and age of the child, current employment status of the mother, educational status of the partner, number of under-5 children in the household, source of drinking water and mother's anemia status were found to be statistically significant determinants of severity levels of childhood anemia.
\end{abstract}

Conclusions: The likelihoods of being severely/moderately anemic as compared to being mildly/non-anemic, and being severely/moderately/mildly anemic as compared to being non-anemic were similar for a given variable keeping all others. Long term and short term nutritional status of young aged children, access to health and nutritional education, and access to safe drinking water should be improved by the concerned body.

Keywords: Anemia, Children aged 6-59 months, Determinants, Ordinal logistic regression, Severity levels

Abbreviations: AIDS, Acquired immunodeficiency syndrome; CSA, Central statistical agency; D, Deviance test statistic; EDHS, Ethiopian demographic and health survey; HIV, Human immunodeficiency virus; OR, Odds ratio; POM, Proportional odds model; WHO, World Health Organization

Correspondence: mkindief@gmail.com

Department of Epidemiology and Biostatistics, Institute of public Health,

University of Gondar, Gondar, Ethiopia 


\section{Background}

Anemia is a condition characterized by a low level of hemoglobin in the blood [1]. Although it affects individuals in all stages of life, preschool children and pregnant women are highly vulnerable. Anemia is a widespread public health problem, and severe anemia is a significant cause of childhood mortality [2]. World Health Organization (WHO) considers anemia prevalence over $40 \%$ as a major public health problem, between 20 and $40 \%$ as a moderate public health problem, and between 5 and $20 \%$ as a mild public health problem [1]. High prevalence of anemia and its negative consequences for children's health, especially for their growth and development, have made anemia as an important public health problem, given the difficulty in implementing effective measures for controlling it [3]. Therefore, to design effective intervention strategies in populations where anemia is common, understanding determinants of anemia and their individual strength of association has a paramount importance [3, 4]. Anemia is multifaceted in etiology. Socioeconomic, nutritional, demographic, environmental and cultural characteristics had been associated with anemia; and the actions required have to encompass pertinent and relevant matters within the context of public health $[3,5]$.

Different levels of severity of anemia (i.e., mild, moderate and severe) are sometimes combined for analysis and reporting. However, if they are reported separately more complete information would be obtained as the differences between them are meaningful theoretically as well as empirically.

The WHO estimated that 1.6 billion people were anemic worldwide, and approximately two-thirds of preschool children in Africa and south East Asia were anemic [6]. Furthermore, according to WHO report, more than half of the world's preschool-age children $(56.3 \%)$ reside in countries where anemia is a major public health problem $[6,7]$. In sub-Saharan Africa, it is a major public health problem among preschool-age children. In this region, much of the national prevalence is estimated to be above $40 \%$ among this group [8]. In Ethiopia, 54 and $44 \%$ of under-five children were anemic in 2005 and 2011, respectively [9].

Even though the government of Ethiopia applied tremendous efforts, childhood anemia was a major public health problem according to WHO criteria. Many researches had been conducted to show its prevalence and associated factors. However, some of the studies were derived from research conducted in specific localized groups which were not representative of the entire Ethiopia [10-12]. Despite the study conducted by Habte et al. was representative of Ethiopia, it only focused on maternal determinants of childhood anemia where socio-demographic and nutritional factors were not considered [13]. Hence, until now there was no population based study permitting generalization about the different severity levels of anemia and its principal determinants among children aged 6 to 59 months in Ethiopia.

Therefore, the present study aimed to identify the determinants associated with different severity levels of anemia among children aged 6 to 59 months in Ethiopia. It was hoped that the results of the study will help to improve policy makers' understanding for effective and efficient application of rational planning and allocation of resources for preventive and control actions against anemia among children in the country.

\section{Methods \\ Study design and sample size}

The study was further analysis of the 2011 Ethiopian Demographic and Health survey (EDHS) data. EDHS is periodical survey with five years interval, sometimes different from five with special cases. The 2011 EDHS was conducted on a nationally representative sample of nine regions and two city administrations of the country. It was conducted from September 2010 to January 2011 to provide current and reliable data on fertility and family planning behavior, child mortality, adult and maternal mortality, children's nutritional status, use of maternal and child health services, knowledge of HIV/AIDS, and prevalence of HIV/AIDS and anemia. Samples were selected using stratified two-stage cluster design technique taking census enumeration areas as the sampling units. In the first stage, 624 clusters of enumeration areas were selected from the list of the 2007 Population and Housing Census sample frame. A total of 17,817 representative households were selected for the 2011 EDHS. Hemoglobin was measured onsite using battery operated portable Hemacue analyzer from finger prick for all children aged 6-59 months, and women aged 15-49 years. The detail of the methodology is available in the EDHS 2011 report [9]. Only households having children aged 6-59 months were considered for this study. Data of 7636 children aged 6 to 59 months with complete information on the selected predictors of childhood anemia status were used.

\section{Variables and source of data}

The 2011 EDHS data were obtained from Central Statistical Agency (CSA), Addis Ababa, Ethiopia. The outcome variable in this study was anemia status of children aged 6 to 59 months categorized into three: severe or moderate, mild, and non-anemic. Anemia status was determined based on hemoglobin concentration in blood adjusted to altitude. Adjusted concentration $10.0-10.9 \mathrm{~g} / \mathrm{dl}$ was considered as mild anemia, 7.0-9.9 g/dl as moderate anemia and less than $7.0 \mathrm{~g} / \mathrm{dl}$ as severe anemia. 
This study tried to include the most important expected determinants of anemia from various literature reviews [3, 5, 10-19], and their theoretical justification from the source of data [9]. The explanatory variables at individual and household levels included were child's size at birth, sex of child, child's age, stunting status of child, wasting status of child, mother's educational level, husband/partner's educational level, mothers' anemia status, mothers' age, mothers' marital status, mothers' current employment status, place of residence, religion of child, source of drinking water, number of under five years old children in the household and child's birth order.

\section{Method of analysis}

Ordinal logistic regression model was employed because of child anemia status is ordered. Specifically, proportional odds model (POM) was employed because of the following appealing features: (a) it is invariant under several categories as only the signs of the regression coefficients change when the coding of the response variable are inverted [20, 21]; (b) it is invariant under collapsibility of the ordered categories as the regression coefficients do not change when response categories are collapsed or the category definitions are changed [22]; and (c) it produces the most easily interpretable regression coefficients as $\exp (-\beta)$ is the homogenous odds ratio (OR) over all cut-off points summarizing the effects of the explanatory variables on the response variable in a single frequently used measure [20].

The POM for the categorical variable $\mathrm{Y}$ with $\mathrm{C}$ ordered categories and a collection of $P$ explanatory variables for the $\boldsymbol{l}^{\text {th }}$ subject $\boldsymbol{X}_{\boldsymbol{l}}^{\prime}=\left(x_{1 \boldsymbol{l}}, x_{2 l}, \ldots, x_{p l}\right), \boldsymbol{l}=1,2, \ldots, n$ is given as:

$$
\begin{aligned}
\operatorname{logit}\left[Y_{l} \leq i \mid x_{l}\right] & =\log \left[\frac{\pi_{i}\left(X_{l}\right)}{1-\pi_{i}\left(X_{l}\right)}\right] \\
& =\alpha_{i}-\beta_{1} x_{1 l}-\ldots-\beta_{p} x_{p l} \\
& =\alpha_{i}-X_{l}^{\prime} \beta \text { for } i=1,2, \ldots, c-1 ; l=1,2, \ldots, n
\end{aligned}
$$

where $\pi_{i}\left(X_{\boldsymbol{l}}\right)=\operatorname{Pr}\left(Y_{\boldsymbol{l}} \leq i \mid X_{\boldsymbol{l}}\right)$ and $\beta$ is a column vector of $P$ regression coefficients and $\alpha_{i}$ is $i^{\text {th }}$ intercept coefficient.

After the best model has been chosen, test of parallelism was assessed. A non-significant chi-square test of parallelism was taken as evidence that the logit surfaces are parallel and that the odds ratios can be interpreted as constant across all possible cut-off points of the outcome variable.

\section{Results}

\section{Characteristics of the study sample}

From the sampled children, 28.6, 21.7 and $49.7 \%$ were severely or moderately anemic, mildly anemic, and nonanemic, respectively. Out of children who resided in rural areas, $22.0 \%$ were mildly anemic, and $29.6 \%$ were severely or moderately anemic. These figures were 19.9 and $23.5 \%$ for those children who resided in urban areas, respectively (Table 1 ).

\section{Determinants of severity levels of child anemia}

The result of uni-variable ordinal logistic regression analysis indicated that the variables sex $(p$-value $=0.122)$ and marital status $(p$-value $=0.605)$ were not significant at $10 \%$ level. Hence, the final multivariable model excludes sex and marital status from the analysis. For this model the deviance based chi-square test provided a chisquare value of 1429.661 ( $p$-value $<0.0005$ ) which implied that the model had good fit. Furthermore, the Chisquare test of parallelism showed that odds ratios appeared to have held constant across all cut-off points of childhood anemia status for the final model at $5 \%$ level ( $p$-value $=0.071)$. Since the parallel lines assumption was held, the interpretation of the result obtained by modeling severely/moderately anemic versus mildly/nonanemic; and anemic versus non-anemic were the same.

As shown in Table 2, the result indicated that severely stunted children were 1.92 (OR $=1.92$; $95 \% \mathrm{CI}$ : 1.71 $2.15 ; p$-value $<0.0005)$ times more likely to be at higher anemia status as compared to non-stunted children. Similarly, moderately stunted children were 1.26 ( $\mathrm{OR}=1.26$; $95 \%$ CI: $1.13-1.41 ; p$-value < 0.0005$)$ times more likely to be at higher anemia status as compared to those who were non-stunted.

As compared to non-wasted children, being at higher anemia status was 1.42 (OR $=1.42 ; 95 \% \mathrm{CI}$ : $1.09-1.85$; $p$-value $=0.01)$ and $1.30(\mathrm{OR}=1.30 ; 95 \% \mathrm{CI}: 1.11-1.52$; $p$-value $=0.001)$ times more likely for severely wasted and moderately wasted children, respectively.

The estimate implied that children in the age range of 6 to 11 months were 5.05 (OR =5.05; $95 \% \mathrm{CI}: 4.25$ - 5.99; $p$-value $<0.0005)$ times more likely to be at higher anemia status as compared to those in the age range of 48 to 59 months. Similarly, the likelihood of being at higher anemia status was 3.97 (OR =3.97; $95 \% \mathrm{CI}$ : 3.45 - 4.57; $p$-value $<0.0005)$ times higher for children in the age range of 12 to 23 months compared to those in the age range of 48 to 59 months.

Furthermore, the results illustrated that the odds of being at higher anemia status was higher for children from non-employed mothers $(\mathrm{OR}=1.13$; $95 \% \mathrm{CL}$ : $1.02-$ $1.25 ; p$-value $=0.051$ )

On the other hand, the odds of being at higher anemia status were lower for children whose households used improved source of drinking water $(\mathrm{OR}=0.87$; $95 \% \mathrm{CL}$ : $0.79-0.96 ; p$-value $=0.006)$, whose mothers' partners $/$ husbands were at primary educational level as compared to illiterate $(\mathrm{OR}=0.86 ; 95 \% \mathrm{CL}: 0.77-0.95$; $p$-value $=0.004)$. 
Table 1 Percentage distribution of anemia status and covariates

\begin{tabular}{|c|c|c|c|c|c|}
\hline \multirow[t]{2}{*}{ Variables } & \multirow[t]{2}{*}{ Categories } & \multicolumn{3}{|c|}{ Child's Anemia status } & \multirow[t]{2}{*}{ Total } \\
\hline & & Non-anemic & Mild & Severe or moderate & \\
\hline \multirow[t]{4}{*}{ Mother's age (years) } & $15-24$ & $47.7 \%$ & $22.3 \%$ & $30.0 \%$ & $22.2 \%$ \\
\hline & $25-29$ & $50.2 \%$ & $21.1 \%$ & $28.7 \%$ & $31.8 \%$ \\
\hline & $30-34$ & $48.2 \%$ & $21.8 \%$ & $30.0 \%$ & $21.4 \%$ \\
\hline & $35-49$ & $52.1 \%$ & $21.8 \%$ & $26.1 \%$ & $24.7 \%$ \\
\hline \multirow[t]{2}{*}{ Type of place of residence } & Rural & $48.4 \%$ & $22.0 \%$ & $29.6 \%$ & $84.6 \%$ \\
\hline & Urban & $56.7 \%$ & $19.9 \%$ & $23.5 \%$ & $15.4 \%$ \\
\hline \multirow[t]{2}{*}{ Mother's educational level } & Primary, Secondary or higher & $55.5 \%$ & $21.5 \%$ & $23.0 \%$ & $29.0 \%$ \\
\hline & Illiterate & $47.3 \%$ & $21.8 \%$ & $30.9 \%$ & $70.9 \%$ \\
\hline \multirow[t]{2}{*}{ Source of drinking water supply } & Improved & $52.9 \%$ & $20.6 \%$ & $26.5 \%$ & $50.5 \%$ \\
\hline & Non-improved & $46.4 \%$ & $22.8 \%$ & $30.8 \%$ & $49.5 \%$ \\
\hline \multirow[t]{3}{*}{ Religion } & Orthodox & $62.6 \%$ & $19.0 \%$ & $18.4 \%$ & $32.6 \%$ \\
\hline & Protestant & $58.0 \%$ & $22.9 \%$ & $19.1 \%$ & $20.9 \%$ \\
\hline & Muslim & $37.0 \%$ & $23.0 \%$ & $40.0 \%$ & $46.6 \%$ \\
\hline \multirow[t]{3}{*}{ Number of children under 5 in household } & 3 or above & $42.9 \%$ & $22.6 \%$ & $34.6 \%$ & $18.7 \%$ \\
\hline & Two & $48.2 \%$ & $22.2 \%$ & $29.5 \%$ & $48.5 \%$ \\
\hline & One & $55.8 \%$ & $20.4 \%$ & $23.9 \%$ & $32.8 \%$ \\
\hline \multirow[t]{3}{*}{ mother's anemia status } & Severe or moderate & $33.8 \%$ & $22.2 \%$ & $44.0 \%$ & $7.3 \%$ \\
\hline & Mild & $38.7 \%$ & $23.9 \%$ & $37.4 \%$ & $16.5 \%$ \\
\hline & Non-anemic & $53.6 \%$ & $21.1 \%$ & $25.2 \%$ & $76.1 \%$ \\
\hline \multirow[t]{2}{*}{ Mother's marital status } & Currently in union/living with a man & $49.5 \%$ & $21.6 \%$ & $28.8 \%$ & $93.5 \%$ \\
\hline & Formerly in union/living with a man & $52.4 \%$ & $22.2 \%$ & $25.4 \%$ & $6.4 \%$ \\
\hline \multirow[t]{3}{*}{ Husband/partner's education level } & Secondary or higher & $56.2 \%$ & $19.1 \%$ & $24.7 \%$ & $9.8 \%$ \\
\hline & Primary & $53.7 \%$ & $22.6 \%$ & $23.7 \%$ & $37.1 \%$ \\
\hline & Illiterate & $45.7 \%$ & $21.5 \%$ & $32.8 \%$ & $53.1 \%$ \\
\hline \multirow[t]{2}{*}{ Mother's current employment status } & Not working & $47.3 \%$ & $22.1 \%$ & $30.6 \%$ & $69.6 \%$ \\
\hline & Working & $55.2 \%$ & $20.7 \%$ & $24.1 \%$ & $30.4 \%$ \\
\hline \multirow[t]{4}{*}{ Birth order number } & $6+$ & $46.9 \%$ & $23.7 \%$ & $29.4 \%$ & $26.5 \%$ \\
\hline & $4-5$ & $47.2 \%$ & $22.4 \%$ & $30.4 \%$ & $23.7 \%$ \\
\hline & $2-3$ & $51.0 \%$ & $20.6 \%$ & $28.4 \%$ & $31.7 \%$ \\
\hline & 1 & $54.8 \%$ & $19.7 \%$ & $25.6 \%$ & $18.1 \%$ \\
\hline \multirow[t]{2}{*}{ Sex of child } & Male & $49.6 \%$ & $21.2 \%$ & $29.2 \%$ & $51.2 \%$ \\
\hline & Female & $49.8 \%$ & $22.2 \%$ & $28.1 \%$ & $48.8 \%$ \\
\hline \multirow[t]{3}{*}{ Child's Size at birth } & Large & $51.0 \%$ & $22.2 \%$ & $26.8 \%$ & $29.6 \%$ \\
\hline & Average & $52.0 \%$ & $20.3 \%$ & $27.7 \%$ & $39.7 \%$ \\
\hline & Small & $45.5 \%$ & $22.9 \%$ & $31.6 \%$ & $30.8 \%$ \\
\hline \multirow[t]{5}{*}{ child age grouped } & $6-11$ & $30.5 \%$ & $26.5 \%$ & $43.0 \%$ & $10.8 \%$ \\
\hline & $12-23$ & $36.2 \%$ & $22.9 \%$ & $40.9 \%$ & $20.5 \%$ \\
\hline & $24-35$ & $47.8 \%$ & $21.9 \%$ & $30.3 \%$ & $21.9 \%$ \\
\hline & $36-47$ & $57.0 \%$ & $20.5 \%$ & $22.6 \%$ & $24.0 \%$ \\
\hline & $48-59$ & $65.1 \%$ & $19.3 \%$ & $15.6 \%$ & $22.8 \%$ \\
\hline
\end{tabular}


Table 1 Percentage distribution of anemia status and covariates (Continued)

\begin{tabular}{llllrr}
\hline Wasting status of Child & Severely wasted & $33.5 \%$ & $21.1 \%$ & $45.4 \%$ & $2.9 \%$ \\
& Moderately wasted & $38.0 \%$ & $25.4 \%$ & $36.6 \%$ & $8.7 \%$ \\
& Non-wasted & $51.4 \%$ & $21.3 \%$ & $27.3 \%$ & $88.6 \%$ \\
Stunting status of Child & Severely stunted & $40.0 \%$ & $22.9 \%$ & $37.1 \%$ & $22 \%$ \\
& Moderately stunted & $51.5 \%$ & $21.7 \%$ & $26.8 \%$ & $24.3 \%$ \\
& Non-stunted & $53.0 \%$ & $21.1 \%$ & $25.8 \%$ & $53 \%$ \\
Total & & $49.7 \%$ & $21.7 \%$ & $28.6 \%$ & $100 \%$ \\
\hline
\end{tabular}

The results showed that the odds of being at higher anemia status were higher for children from households with two $(\mathrm{OR}=1.17 ; 95 \% \mathrm{CL}$ : $1.05-1.30 ; p$-value $=$ $0.005)$ and three or more (OR $=1.30$; $95 \%$ CL: $1.13-$ 1.49; $p$-value $<0.0005)$ under-five children. Similarly, the odds of being at higher anemia status were higher for children whose mothers were at higher severity level of anemia; mothers with Severe/moderate $(\mathrm{OR}=$ 1.84; $95 \%$ CL: $1.55-2.18 ; p$-value $<0.005)$ and mild $(\mathrm{OR}=1.57 ; 95 \% \mathrm{CL}: 1.40-1.77 ; p$-value $<0.0005)$.

In this study, the religious affiliation of the child was also found out to be significantly associated with children anemia status. The likelihood of being at higher anemia status to Orthodox and Protestant children were $62.3 \%$ $(\mathrm{OR}=0.38 ; 95 \% \mathrm{CL}: 0.34-0.42 ; p$-value $<0.0005)$ and $56.1 \%(\mathrm{OR}=0.44 ; 95 \%$ CL: $0.39-0.50 ; p$-value $<0.0005)$ lower than those children whose mothers are Muslim, respectively.

\section{Discussions}

From the Chi-square test of parallelism, the likelihood of being severely/moderately anemic as compared to being mildly/non-anemic and the likelihood of being severely/ moderately/mildly anemic as compared to being nonanemic was similar for a given variable keeping all others among variables studied.

The result indicated that severely/moderately stunted children were more likely to be severely/moderately anemic as compared to non-stunted. This result was consistent with the finding that stunting was associated with increased risk of anemia in children 6 to 59 months, and that anemia prevalence in children with stunting was twice that of children with normal stature [14]. It was also consistent with the finding that stunted children were 2.7 times more likely to be anemic than their counterpart [10]. This finding also agreed with other studies conducted in Bangladesh [23], Brazil [24], Burma [25] and Kenya [26]. Moreover, the likelihood of being anemic was high in wasted children. Since stunting and wasting are long-term and short-term indicators of malnutrition, the implication of the results was that undernourished children experience higher risk of developing anemia as compared to nourished children. The possible explanation could be due to the fact that anemia and malnutrition often share common causes; it is expected that multiple types of malnutrition would coexist in the same individuals, and increase the development of anemia in synergetic manner. Besides, the gastrointestinal epithelium disturbance in malnourished individuals may reduce absorption, and contribute towards development and worsening of anemia [11]. Consequently, low hemoglobin level may also compromise the linear growth of the children [27].

The results also showed that the likelihood of children in the age range of 6 to 23 months being severely/moderately anemic was higher than those in the age range of 48 to 59 months, holding all other variables constant. The result of the study was consistent with the result of various studies [11, 15-17]. One of the possible explanations for the higher likelihood of anemia might be related to low balanced nutritional intakes that may not be sufficient for their rapid growth related demands [28]. The other possible reasons might be due to the fact that poor infant and young children feeding practices particularly timely initiation of complementary food is low in Ethiopia as evidenced by published data of 2005 and 2011 EDHS survey [29].

The results revealed that the odds of being severely/ moderately anemic were higher for children from nonemployed mothers. This result was consistent with the finding that children of working mothers were at lower risk of anemia [14].

Moreover, the odds of being severely/moderately anemic were higher for children whose households used non-improved source of drinking water. This result agreed with the result that the occurrence of anemia was 1.68 times higher for children from households that consume untreated water as compared to those children from households that consume treated water [14]. Precarious sanitation conditions are linked with anemia, even if indirectly. Since such conditions are associated with greater number of infectious and parasitic diseases, which in turn contributed towards diminishing the hemoglobin levels.

From the results, the odds of being severely/moderately anemic were higher for children whose mothers' 
Table 2 Parameter estimates of related covariates in the final proportional odds model

\begin{tabular}{|c|c|c|c|c|c|}
\hline \multirow[t]{2}{*}{ Variables } & \multirow[t]{2}{*}{ Categories } & \multirow[t]{2}{*}{ OR } & \multirow[t]{2}{*}{$P$-value } & \multicolumn{2}{|c|}{$95 \% \mathrm{Cl}$ of $\mathrm{OR}$} \\
\hline & & & & LB & UB \\
\hline \multirow[t]{4}{*}{ Mother's age (years) } & $15-24$ & 1.07 & 0.522 & 0.88 & 1.29 \\
\hline & $25-29$ & 1.03 & 0.673 & 0.88 & 1.21 \\
\hline & $30-34$ & 1.12 & 0.11 & 0.97 & 1.30 \\
\hline & $35-49$ (ref) & & & & \\
\hline \multirow[t]{2}{*}{ Type of place of residence } & Rural & 1.04 & 0.582 & 0.90 & 1.21 \\
\hline & Urban (ref) & & & & \\
\hline \multirow[t]{2}{*}{ Mother's educational level } & Primary/Secondary/higher & 0.92 & 0.186 & 0.82 & 1.04 \\
\hline & No education (ref) & & & & \\
\hline \multirow[t]{2}{*}{ Source of drinking water supply } & Improved & 0.87 & 0.006 & 0.79 & 0.96 \\
\hline & Non improved (ref) & & & & \\
\hline \multirow[t]{3}{*}{ Religion } & Orthodox & 0.38 & .000 & 0.34 & 0.42 \\
\hline & Protestant & 0.44 & .000 & 0.39 & 0.50 \\
\hline & Muslim (ref) & & & & \\
\hline \multirow[t]{3}{*}{ Number of children 5 and under in household } & 3 or above & 1.30 & .000 & 1.13 & 1.49 \\
\hline & Two & 1.17 & 0.005 & 1.05 & 1.30 \\
\hline & One (ref) & & & & \\
\hline \multirow[t]{3}{*}{ Mother's anemia status } & Severe or moderate & 1.84 & .000 & 1.55 & 2.19 \\
\hline & Mild & 1.57 & .000 & 1.40 & 1.78 \\
\hline & Not anemic (ref) & & & & \\
\hline \multirow[t]{3}{*}{ Husband/partner's education level } & Secondary or higher & 1.04 & 0.667 & 0.86 & 1.26 \\
\hline & Primary & 0.86 & 0.004 & 0.77 & 0.95 \\
\hline & No education (ref) & & & & \\
\hline \multirow[t]{2}{*}{ Mother's current employment status } & Not working & 1.13 & 0.015 & 1.02 & 1.25 \\
\hline & Working (ref) & & & & \\
\hline \multirow[t]{4}{*}{ Birth order number } & $6+$ & 1.05 & 0.655 & 0.86 & 1.28 \\
\hline & $4-5$ & 1.13 & 0.188 & 0.94 & 1.35 \\
\hline & $2-3$ & 1.01 & 0.922 & 0.87 & 1.17 \\
\hline & 1 (ref) & & & & \\
\hline \multirow[t]{3}{*}{ Child's Size at birth } & Large & 0.97 & 0.557 & 0.86 & 1.09 \\
\hline & Average & 0.95 & 0.308 & 0.85 & 1.05 \\
\hline & Small (ref) & & & & \\
\hline \multirow[t]{5}{*}{ Child age (years) } & $6-11$ & 5.06 & .000 & 4.25 & 6.01 \\
\hline & $12-23$ & 3.98 & .000 & 3.45 & 4.59 \\
\hline & $24-35$ & 2.11 & .000 & 1.83 & 2.42 \\
\hline & $36-47$ & 1.47 & .000 & 1.28 & 1.68 \\
\hline & $48-59$ (ref) & & & & \\
\hline \multirow[t]{3}{*}{ Wasting status of Child } & Severe & 1.42 & 0.01 & 1.09 & 1.85 \\
\hline & Moderate & 1.30 & 0.001 & 1.11 & 1.52 \\
\hline & Not wasted (ref) & & & & \\
\hline \multirow[t]{3}{*}{ Stunting status of Child } & Severe & 1.92 & .000 & 1.71 & 2.15 \\
\hline & Moderate & 1.26 & .000 & 1.13 & 1.41 \\
\hline & Not stunted (ref) & 1.07 & & & \\
\hline
\end{tabular}


partners/husbands were illiterate. Related study showed that, education has a relationship with the capacity to grasp the knowledge needed for adequate healthcare and nutrition for children; just as it provides a chance to join the labor market and probably better socioeconomic conditions [18]. This may be because educated partners have better health and nutrition knowledge and child rearing practices than uneducated ones which both contribute to improved child health. Therefore, it is useful to improve partners' access to education in all areas in order to address the problem through improving their income earning capacity and also enhancing the quality of care and attention they can provide to their children.

Additionally, at the household level, the results indicated that the higher anemia status was more likely for children from households with greater number of children under the age of five years in Ethiopia. This agreed with the result of other study done in Brazil [19]. The possible justification could be due to the fact that the household with greater number of children has high demand and expenditure for food to satisfy the needs of members of the family. In conjunction, this may worsen the quality of care for children, and increase the risk of anemia not only for children but also for adults.

The results also implied that higher child anemia status was more likely for children from severely/moderately anemic and mildly anemic mothers compared to those from non-anemic mothers. This result was consistent with other finding that maternal anemia was associated with increased risk of anemia in children 6 to 59 months [14]. The possible reason might be related to shared socio-economic status of the family which may affect both children and their mothers, and leading to anemia.

Based on the religious affiliation of the child, the likelihood of severe/moderate anemia to Orthodox and Protestant children are lower than those Muslim children. Here religious affiliation has impact on severity levels of child anemia status. This result was supported by other related studies conducted in North-East India [30] and India [31].

\section{Limitations}

The data used was secondary which was obtained from cross sectional survey. As a result there may be causeeffect relationship dilemma. Furthermore, this study did not include all modifiable risk factors like current status/ history of infectious disease particularly those which have a potential role in dysregulating erythropoiesis such as HIV, intestinal parasites and malaria. Moreover, in this study only hemoglobin value was measured to define anemia. However, in the areas where micronutrient deficiencies and hemoglobinopathies are prevalent measuring serum hematinics level and detecting hemoglobinopathies along with hemoglobin level gives appealing evidences for public health intervention.

\section{Conclusions}

The likelihoods of being severely/moderately anemic as compared to being mildly/non-anemic and of being severely/moderately/mildly anemic as compared to being non-anemic were similar for a given variable keeping all others variables. The study revealed that nutritional status of the child (wasting status and stunting status), current employment status of mother, religion of the child, educational status of partner, age of child, number of children under-5 in the household, source of drinking water and mother's anemia status were the most important determinants of severity levels of child anemia in Ethiopia in 2011. Consequently, a number of interventions required to reduce high prevalence of anemia for children in Ethiopia were recommended. These include: First, Policies and plans have to be put in place to reduce the prevalence of mothers' anemia. Second, Efforts like health, nutritional and family planning education, and follow up of both long term and short term nutritional status should be made to young aged children. Third, Improve partners' access to education in all areas to enhance the quality of care and attention they can provide to their children. Finally, Efforts should be made to improve access to safe drinking water and job opportunities to mothers.

\section{Additional file}

Additional file 1: NUTN-D-15-00006 last used data (an excel file up on which all the results of the manuscript was based). (XLS $1979 \mathrm{~kb}$ )

\section{Acknowledgement \\ I would like to thank the Ethiopian Central Statistics Agency for providing me with all the relevant secondary data used in this study. Next to this, I also would like to express my deepest gratitude to my wife Betelhem Tigabu for her continued support and initiation. Finally, I would like to thank all who directly or indirectly supported me.}

Funding

I did not receive external funding for this research.

Availability of data and materials

Fully anonymized data supporting the findings of this study can be found in Additional file 1.

\section{Authors' contributions}

KFM designed the study, performed the statistical analysis, interpreted the results and prepared the manuscript. The author also read and approved the final manuscript.

\section{Author's information}

The author currently works at University of Gondar, Gondar, Ethiopia. He serves as a Lecturer and Researcher in Epidemiology and Biostatistics Department, Institute of Public Health. He obtained both Master of Science in Biostatistics and Bachelor of Science in Statistics from University of Gondar, Ethiopia. 


\section{Competing interests}

The author declares that he has no competing interests.

\section{Consent for publication}

This manuscript does not contain any individual person's data.

\section{Ethics approval and consent to participate}

Ethical clearance for the 2011 EDHS was provided by the Ethiopian Health and Nutrition Research Institute (EHNRI) Review Board, the National Research Ethics Review Committee (NRERC) at the Ministry of Science and Technology, the Institutional Review Board of ICF International, and the communicable disease control (CDC). Additionally, written consent for participation was obtained from each respondent; consent for children was obtained through the parents, caregivers or guardians. However, the dataset of the 2011 EDHS is not available as a public domain survey dataset. The author requested access to the data from Director of Central Statistics Agency of Ethiopia and access was granted to use the data for this research.

Received: 20 July 2015 Accepted: 11 August 2016

Published online: 17 August 2016

\section{References}

1. WHO. Iron Deficiency Anaemia: Assessment, Prevention, and Control. A guide for programme managers. Geneva: World Heal Organ; 2001. 114.

2. Brabin BJ, Hakimi M, Pelletier D. Iron-deficiency anemia: reexamining the nature and magnitude of the public health problem an analysis of anemia and pregnancy-related maternal mortality. J Nutr. 2001;131:604-15.

3. Stoltzfus RJ. Defining iron-deficiency anemia in public health terms: a time for reflection. J Nutr. 2001;131(2S-2):697S-700. discussion 700S - 701S.

4. $\mathrm{WHO} / \mathrm{CDC}$. Assessing the iron status of populations: report of a joint WHO/ CDC technical consultation on the assessment of iron status at the population level. Geneva: WHO Library Cataloguing-in-Publication Data; 2007. p. 1-35.

5. Mora JO. Iron supplementation: overcoming technical and practical barriers. J Nutr. 2002;132 Suppl 4:853S-5.

6. Benoist B de, McLean E, Egll I, Cogswell M. Worldwide prevalence of anaemia 1993-2005. Geneva: WHO Global Database on Anaemia; 2008. vi+41 pp.

7. Mclean E, Cogswell M, Egli I, Wojdyla D, De Benoist B. Worldwide prevalence of anemia, WHO vitamin and mineral nutrition information system, 1993-2005. Public Health Nutr. 2009;12(4):444-54.

8. Soares Magalhães RJ, Clements AC. Spatial heterogeneity of haemoglobin concentration in preschool-age children in sub-Saharan Africa. Bull World Health Organ. 2011;89(6):459-68. doi:10.2471/BLT.10.083568.

9. Central Statistical Agency [Ethiopia] and ICF International. Ethiopia Demographic and Health Survey 2011. Health San Francisco. 2012.

10. Woldie H, Kebede Y, Tariku A. Factors Associated with Anemia among Children Aged 6-23 Months Attending Growth Monitoring at Tsitsika Health Center, Wag-Himra Zone, Northeast Ethiopia. Journal of Nutrition and Metabolism. 2015. doi: 10.1155/2015/928632.

11. Gebreegziabiher G, Etana B, Niggusie D. Determinants of Anemia among Children Aged 6-59 Months Living in Kilte Awulaelo Woreda, Northern Ethiopia. Anemia. 2014. doi: 10.1155/2014/245870.

12. Getaneh T, Girma T, Belachew T, Teklemariam S. The utility of pallor detecting anemia in under five years old children. Ethiop Med J. 2000;38:77-84.

13. Habte D, Asrat K, Magafu MGMD, Ali IM, Benti T, Abtew W, et al. Maternal risk factors for childhood anaemia in Ethiopia. Afr J Reprod Health. 2013;17:110-8.

14. Cotta RMM, de Cc OF, Magalhaes KA, Ribeiro AQ, Sant'Ana LF Da R, Priore $\mathrm{SE}$, et al. Social and biological determinants of iron deficiency anemia. Cad Saude Publica. 2011;27 Suppl 2:S309-20.

15. Cardoso MA, Scopel KKG, Muniz PT, Villamor E, Ferreira MU. Underlying factors associated with anemia in Amazonian children: a population-based, cross-sectional study. PLoS One. 2012;7(5):e36341.

16. Oliveira MAA, Osório MM, Raposo MC. Socioeconomic and dietary risk factors for anemia in children aged 6 to 59 months. J Pediatria (Rio J). 2007;83(1):39-46.

17. Konstantyner T, Roma Oliveira TC, De Aguiar Carrazedo Taddei JA. Risk factors for anemia among Brazilian infants from the 2006 national demographic health survey. Anemia. 2012. doi: 10.1155/2012/850681.
18. Leal LP, Batista Filho M, de Lira PIC, Figueiroa JN, Osório MM. Prevalence of anemia and associated factors in children aged 6-59 months in Pernambuco. Northeastern Brazil Revista de Saúde Pública. 2011:45(3):457-66.

19. Silva LSM, Giugliani ERJ, Aerts DRGC. Prevalência e determinates de anemia em crianças de Porto Alegre, RS. Brasil Revista de Saude Publica. 2001;35(1):66-73.

20. McCullagh P. Regression models for ordinal data. J R Stat Soc Ser B Methodol. 1980;42(2):109-42.

21. Peterson B, Harrell FE, Petersont B. Partial proportional odds models for ordinal response variables. J R Stat Soc Ser C Applied Stat. 1990;39(2):205-17.

22. Greenland S. Alternative models for ordinal logistic regression. Stat Med. 1994;13(16):1665-77.

23. Uddin MK, Sardar MH, Hossain MZ, Alam MM, Bhuya MF, Uddin MM, Rahman MJ. Prevalence of anaemia in children of 6 months to 59 months in Narayanganj. Bangladesh J Dhaka Medical College. 2010;19(2):126-30.

24. Osório MM, Lira PI, Batista-Filho M, Ashworth A. Prevalence of anemia in children 6-59 months old in the state of Pernambuco, Brazil. Revista Panamericana de Salud Pu'Blica. 2001;10(2):101-7.

25. Zhao A, Zhang Y, Peng Y, Li J, Yang T, Liu Z, et al. Prevalence of anemia and its risk factors among children 6-36 months old in Burma. AmJTrop Med Hyg. 2012;87(2):306-11.

26. Foote EM, Sullivan KM, Ruth LJ, Oremo J, Sadumah I, Williams TN, Suchdev PS. Determinants of anemia among preschool children in rural, Western Kenya. Am J Trop Med Hyg. 2013;88(4):757-64.

27. Soliman AT, Al Dabbagh MM, Habboub AH, Adel A, Humaidy NA, Abushahin A. Linear growth in children with iron deficiency anemia before and after treatment. J Trop Pediatr. 2009;55(5):324-7. doi:10.1093/tropej/fmp011.

28. Pita GM, Jiménez S, Basabe B, García RG, Macías C, Selva L, et al. Anemia in children under five years old in Eastern Cuba, 2005-2011. MEDICC Rev. 2014;16(1):16-23.

29. Disha A, Tharaney M, Abebe Y, Alayon S, Winnard K. Factors associated with infant and young child feeding practices in Amhara region and nationally in Ethiopia: analysis of the 2005 and 2011 demographic and health surveys. Washington, DC: Alive and Thrive; 2015.

30. Dey S, Goswami S, Dey T. Identifying predictors of childhood anaemia in North-East India. J Heal Popul Nutr. 2013;31(4):462-70.

31. Goswmai S, Das KK. Socio-economic and demographic determinants of childhood anemia. J Pediatr (Rio J). 2015;91(5):471-7.

\section{Submit your next manuscript to BioMed Central and we will help you at every step:}

- We accept pre-submission inquiries

- Our selector tool helps you to find the most relevant journal

- We provide round the clock customer support

- Convenient online submission

- Thorough peer review

- Inclusion in PubMed and all major indexing services

- Maximum visibility for your research

Submit your manuscript at www.biomedcentral.com/submit
Biomed Central 